\title{
Consum d'oxigen postexercici després d'un exercici continu i un altre d'intervals en tapís rodant
}

\author{
Post-Exercise Oxygen Consumption after Continuous \\ and Interval Exercise on a Treadmill
}

ALEJANDRO CAMPS OLMEDO

Departament d'Esport i informàtica. Facultat de l'Esport

Universidad Pablo de Olavide
Autor per a la correspondència

Alejando Camps OImedo

acamps@upo.es

Resum

El propòsit d'aquest estudi va ser comparar la despesa calòrica total (despesa en activitat + EPOC -excessiu consum d'oxigen postexercici-) $(n=10)$ realitzant: 1$)$ un exercici de cursa contínua de 30 minuts $\mathrm{Al} 65 \% \mathrm{VO}_{2 \text { màx }}$ i 2) un exercici de cursa a intervals de 30 minuts, a raó de 15 tandes d'un minut de treball al $90 \%$ del $\mathrm{VO}_{2 \text { màx }}$, seguit d'un minut de descans passiu, realitzat en bipedestació. Deu estudiants de Ciències de l'Activitat Física i de l'Esport (edat: $23 \pm 2,8$ anys; pes: $70 \pm 8$,8 kg; alçada: $175,7 \pm 5,2 \mathrm{~cm}$ ) van participar en l'estudi. Les proves de l'estudi es van realitzar en tapís rodant. Tots els subjectes van realitzar ambdues proves en dies no consecutius. La FC es va registrar contínuament durant l'exercici. Els gasos espirats van ser analitzats amb un analitzador de gasos estàndard. Els resultats van mostrar un treball total similar, en què no es van trobar diferències significatives (CON: 358,60 $\pm 70,82 \mathrm{~kJ}$, INT: $352,99 \pm 63,56 \mathrm{~kJ})$, el consum calòric total va ser més gran $(P=0,037)$ en el d'intervals $(398,5 \pm 98,5 \mathrm{kcal})$ que en el continu $(343,2 \pm 75,3 \mathrm{kcal})$, el consum calòric en la recuperació va ser més gran $(P=0,031)$ en el d'intervals $(85 \pm 66,8 \mathrm{kcal})$ que en el continu $(43,5 \pm 26,8 \mathrm{kcal})$. En conclusió, en aquest estudi es demostra que la despesa calòrica total és més gran en un exercici d'intervals d'alta intensitat que en un exercici continu de baixa intensitat per a temps i càrregues de treball iguals. A més a més, la despesa calòrica en l'exercici d'intervals és més gran tant durant l'exercici com durant la recuperació.

Paraules clau: exercici, consum calòric, EPOC (excessiu consum d'oxigen postexercici)

\begin{abstract}
Post-Exercise Oxygen Consumption after Continuous and Interval Exercise on a Treadmill

The purpose of this study was to compare total calorie expenditure [activity expenditure + EPOC (excessive post-exercise oxygen consumption)] $(\mathrm{n}=10)$ when doing 1) a 30-minute tempo run at $65 \%$ VO2 $2_{\text {max }}$ and 2) 30 minutes of interval training with 15 one-minute activities working at $90 \%$ of $\mathrm{VO} 2_{\text {max }}$ followed by a minute of passive rest in the standing position. Ten sports science students (age: $23 \pm 2.8$ years, weight: $70 \pm 8.8 \mathrm{~kg}$, height: $175.7 \pm 5.2 \mathrm{~cm}$ ) took part in the study and the study tests were conducted on a treadmill. All the subjects performed both tests on non-consecutive days. Their HR was recorded continuously during exercise. Expired gases were analyzed with a standard gas analyzer. The results showed similar total work with no significant differences (CON: $358.60 \pm 70.82 \mathrm{~kJ}$, INT: $352.99 \pm 63.56 \mathrm{~kJ})$, total calorie expenditure was higher $(\mathrm{P}=0.037)$ in interval $(398.5 \pm 98.5 \mathrm{kcal})$ than in continuous $(343.2 \pm 75.3 \mathrm{kcal})$ and calorie expenditure in recovery was higher $(\mathrm{P}=0.031)$ in interval $(85 \pm 66.8 \mathrm{kcal})$ than in continuous $(43.5 \pm 26.8 \mathrm{kcal})$. In conclusion, this study shows that the total caloric expenditure is greater in high intensity interval exercise than in low-intensity continuous exercise for equal times and workloads. Furthermore, caloric expenditure in interval exercise is greater both during exercise and during recovery.
\end{abstract}

Keywords: exercise, caloric expenditure, PEOC (post-exercise oxygen consumption)

\section{Introducció}

Gfaesser i Brooks (1984) van anomenar excessive post-exercise oxygen consumption 'excessiu consum d'oxigen postexercici' (EPOC) l'augment del consum d'oxigen per sobre dels seus nivells basals que ocorre després de l'exercici (Bahr, Ingnes, Vaage, Sejersted, \& Newsholme, 1987; Gaesser \& Brooks, 1984). L'EPOC és un factor que cal tenir en compte a l'hora de quantificar la despesa calòrica total de qualsevol ac- tivitat física, ja que s'ha de considerar com a part de la despesa calòrica que la pròpia activitat provoca i que pot arribar a mantenir elevada la taxa metabòlica durant hores després de cesar l'activitat (Binzen, Swan, \& Manore, 2001; González-Alonso, Quistorff, Krustrup, \& Saltin, 2000; Schuenke, Mikat, \& McBride, 2002). Per això és important quantificar l'EPOC en aquells programes d'activitat física encaminats al control i la pèrdua de pes. Sedlock, Fissinger i Melby (1989) van aportar que el 
valor energètic de l'EPOC era equivalent a aproximadament el $10 \%$ de la despesa energètica per activitat després d'una despesa aproximada de $300 \mathrm{kcal}$ al $75 \% \mathrm{VO}_{2 \text { màx }}$. Bahr, Ingnes, Vaage, Sejersted i Newsholme (1987) mostren un EPOC d'aproximadament el $15 \%$ de la despesa calòrica de l'activitat després d'un exercici de 80 minuts al $70 \% \mathrm{VO}_{2 \text { màx }}$.

Si bé la despesa calòrica derivada de l'EPOC és menor que la de l'activitat física en si (Almuzaini, Potteiger, \& Green, 1998; Borsheim \& Bahr, 2003; Gore \& Withers, 1990; Maresh et al., 1992; Schuenke et al., 2002), no és menys cert que la magnitud i duració del fenomen de l'EPOC són majors com més intensa és l'activitat en qüestió (Friedlander, Casazza, \& Horning, 1998; Gore \& Withers, 1990; Romijn, Coyle, Sidossis, Rosenblatt, \& Wolfe, 2000; Thornton \& Potteiger, 2002). Brockman, Berg i Latin (1993) van concloure que l'exercici d'alta intensitat, tan intermitent com continu, produïa un consum d'oxigen més gran durant la recuperació si el comparem amb un exercici de baixa intensitat; aquesta observació és compartida per Gore i Withers (1990), que van mostrar que la intensitat d'exercici va ser el major determinant de l'EPOC i van trobar una relació lineal positiva entre la intensitat de l'exercici i la duració de l'EPOC (amb una duració de 9 hores) en el cas de treballs d'intensitat supramàxima. Altres autors suggereixen que els treballs en intensitats supramàximes $(105 \%$ del $\left.\mathrm{VO}_{2 \text { màx }}\right)$ produeixen un EPOC de més duració que els treballs a intensitats moderades $\left(70-75 \% \mathrm{VO}_{2 \text { màx }}\right)$ (Horton, Pagliassotti, Hobb, \& Hill, 1998; Melanson et al., 2002; Phillips, Green, \& Tarnopolsky, 1996). Quant a les possibles diferències entre subjectes entrenats i no entrenats, Sedlock (1994) no va trobar variacions en la magnitud i duració de l'EPOC en funció del grau d'entrenament. No obstant això, altres autors asseguren que sí que existeixen diferències, essent els entrenats més ràpids en aconseguir els valors de repòs (Haltom et al., 1999; Pritzlaff et al., 2000; A. L. Uusitalo, Huttunen, Hanin, \& Uusitalo, 1998). En estudis recents, McGarvey, Jones i Petersen (2005) demostren que, per temps i càrregues de treball semblants, la magnitud de l'EPOC no canvia.

Aquesta elevació es deu principalment als següents factors: resíntesi de fosfocreatina (PC) en el muscle, depuració de lactat, reestabliment dels magatzems d'oxigen sanguini i muscular, augment de la temperatura, elevació de la freqüència cardíaca i respiratòria i augment de l'activitat hormonal (Gerardo, Córdova, \& González, 2000; Gore \& Withers, 1990). A més a més, hem de tenir en compte que l'activitat física intensa produeix adaptacions en l'àmbit central i perifèric que no es poden aconseguir amb intensitats submàximes i que té notables beneficis per a la salut, com poden ser l'augment del consum d'oxigen, el flux sanguini muscular o el volum sistòlic (Covertino, 1993; Guesbeck et al., 2001; Weltman et al., 1989).

Diversos estudis han investigat l'EPOC produit per exercici d'intensitat moderada (Bahr et al., 1987; Binzen et al., 2001; Gerardo et al., 2000; Gore \& Withers, 1990; Horowits \& Klein, 2001; Kaminsky, Padjen, \& LaHam-Saeger, 1990), però relativament pocs (Friedlander et al., 1998; Haltom et al., 1999; McGarvey, Jones, \& Petersen, 2005) s'han centrat en la comparació de l'EPOC produït per exercici d'alta i moderada intensitat. Per dur a terme una comparació directa del consum d'oxigen durant la recuperació després d'un exercici continu i un altre d'intervals, és important assegurar-se que les variables de l'exercici com la duració i el treball total són el més semblants possible, així com evitar menjar després de l'exercici.

En estudis anteriors s'han utilitzat diferents duracions i treballs (Frielander et al., 1998) o diferents mètodes de determinació de l'EPOC (Haltom et al., 1999; McGarvey et al., 2005), la qual cosa fa difícil la comparació del seus resultats.

Sembla que fragmentant un exercici en dues o més parts iguals i que sumin exactament la mateixa despesa calòrica total durant l'activitat, la suma de cada EPOC és més gran que el que s'obté en una sola sessió (Binzen et al., 2001; Hardman, 2001; Horowitz \& Klein, 2000; Kaminsky et al., 1990; Yoshida et al., 1990). Així, en aquells programes dirigits al control i la pèrdua de pes es podrien fer sessions fraccionades amb l'objectiu d'augmentar la despesa calòrica total (en augmentar l'EPOC). Un altre avantatge del fraccionament seria reduir el risc de lesió articular per sobrecàrrega que comporten lesions seguides de més duració en persones amb sobrepès.

Es va plantejar la hipòtesi que "l'exercici d'intervals d'alta intensitat $\left(90 \% \mathrm{VO}_{2 \text { màx }}\right)$ provoca una despesa calòrica total (exercici + recuperació) més gran que l'exercici continu de moderada intensitat $\left(65 \% \mathrm{VO}_{2 \text { màx }}\right)$ per un treball total similar".

L'objectiu d'aquest estudi va ser determinar si el consum d'oxigen va ser diferent durant la recuperació (fins que els subjectes van aconseguir els nivells basals $\pm 3,5 \mathrm{ml} / \mathrm{kg} / \mathrm{min}$ ) després de realitzar un treball d'intervals $\mathrm{i}$ un altre de continu per temps de treball $\mathrm{i}$ treball total similars i sense cap tipus d'alimentació postexercici. 


\section{Material i mètodes}

\section{Subjectes}

Deu estudiants de Ciències de l'Activitat Física i l'Esport que no feien cap tipus d'entrenament específic (edat: $23 \pm 2,8$ anys; pes: $70 \pm 8,8 \mathrm{~kg}$; alçada: $175,7 \pm 5,2 \mathrm{~cm} ; \mathrm{VO}_{2 \text { màx }} 48,3 \pm 9,1 \mathrm{ml} / \mathrm{kg} / \mathrm{min}$ ) van participar en l'estudi. Els deu subjectes van ser escollits de manera aleatòria d'un total de vint-i-quatre voluntaris i van signar per escrit el seu consentiment a participar en aquest estudi de les característiques del qual havien estat adequadament informats.

\section{Protocol d'estudi}

Totes les mesures d'intercanvi de gasos es van fer utilitzant un analitzador de gasos estàndard (Medgraphics CPX Breeze 6.1. St Paul. MN, USA).

Cada subjecte va anar al laboratori en tres dies separats i a la vegada separats entre ells com a mínim $72 \mathrm{~h}$. El primer dia va consistir en un test incremental per a la determinació del llindar ventilatori (Vt) i el consum d'oxigen màxim $\left(\mathrm{VO}_{2 \operatorname{màx}}\right)$. Vt es va determinar per inspecció visual de les dades com la velocitat, que va causar un augment sistemàtic en l'equivalent ventilatori d'oxigen $\left(\mathrm{V}_{\mathrm{E}} / \mathrm{VO}_{2}\right)$ mentre que l'equivalent ventilatori del $\mathrm{CO}_{2}$ no augmentava. Els subjectes es van familiaritzar amb el tapís rodant (Powerjog J serie Bridgend, Mid Glamorgan, UK) i amb l'ús de la mascareta i la pinça nasal. La freqüència cardíaca (FR) de cada subjecte es va registrar contínuament durant l'exercici amb un telèmetre o pulsòmetre (Polar RS800, Polar Electro Inc., Woodbury, NY). Es va dur a terme un escalfament que consistia a caminar durant $2 \min$ a $6 \mathrm{~km} \cdot \mathrm{h}^{-1}$ i $2 \min$ a $8 \mathrm{~km} \cdot \mathrm{h}^{-1}$ amb una inclinació de l'1\%, seguits d'una recuperació passiva de $3 \mathrm{~min}$. Els subjectes després van fer el test incremental començant amb una velocitat de $8 \mathrm{~km} \cdot \mathrm{h}^{-1}$ amb una inclinació constant de l'1\% i es va augmentar $0,25 \mathrm{~km} \cdot \mathrm{h}^{-1} / 15^{\prime \prime}$ fins a l'esgotament. L'esgotament es va establir en el punt en el qual el subjecte no podia mantenir la velocitat requerida. Es van usar els criteris estàndard $\mathrm{FC}_{\text {màx }}$ teòrica aconseguida, $\mathrm{RER}>1,1$ i fase estacionària del $\mathrm{VO}_{2}$ per confirmar el $\mathrm{VO}_{2 \text { màx }}$ (LaForgia, Withers, Shipp, \& Gore, 1997). Es van utilit-

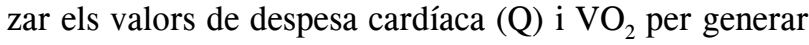
equacions de regressió per determinar la potència/velocitat corresponent a cada percentatge de $\mathrm{VO}_{2 \text { màx }}$.

El segon i el tercer dia es va realitzar el protocol continu o d'intervals, que va ser ordenat aleatòriament.
Els subjectes van ser instruits per evitar exercici intens les 36 hores prèvies al test, així com per registrar la dieta realitzada les 24 hores prèvies al primer test i repetir-la les 24 hores prèvies al segon. Les condicions d'humitat i temperatura es van mantenir en condicions normals ( $60 \%$ i $23^{\circ} \mathrm{C}$ respectivament).

Les proves de l'estudi per a mesurament de l'EPOC després de cursa contínua (30 min a la velocitat corresponent al $\left.65 \% \mathrm{VO}_{2 \text { màx }}\right)$ o a intervals (exercici de cursa a intervals de 30 minuts de duració total, a raó de 15 tandes consecutives d'un minut de treball a la velocitat corresponent al $90 \%$ del $\mathrm{VO}_{2 \operatorname{màx}}$, seguit d'un minut de descans passiu, realitzat en bipedestació) es van realitzar en l'esmentat tapís rodant. La FC de cada subjecte es va registrar contínuament (intervals de $5 \mathrm{~s}$ ) durant l'exercici amb un telèmetre o pulsímetre (Polar RS800, Polar Electro Inc., Woodbury, NY). Els gasos espirats es van analitzar d'una manera continuada (breath-by-breath o 'respiració a respiració') durant l'exercici i la recuperació (mesurant l'EPOC) amb un analitzador de gasos estàndard (Medgraphics CPX Breeze 6.1. St Paul. MN, USA) (fig. 1).

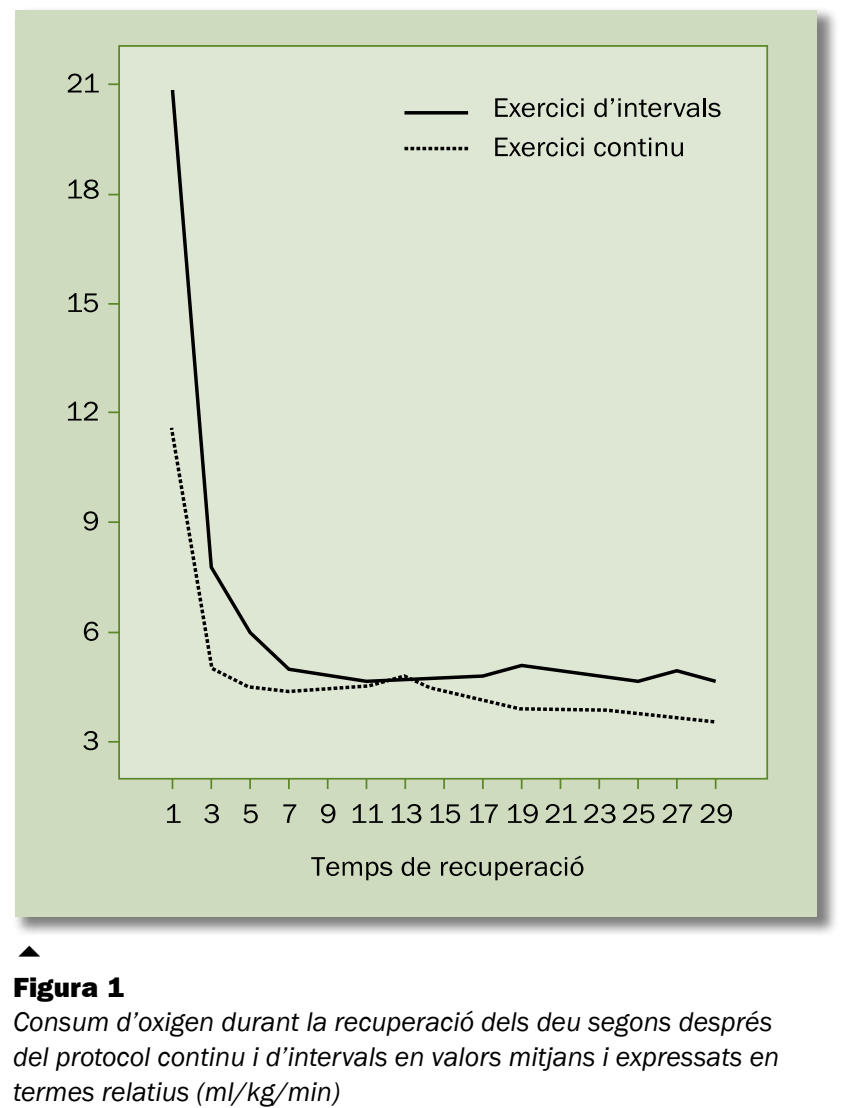


Immediatament finalitzat l'exercici, els subjectes van seure en una cadira fins que els seus valors de $\mathrm{VO}_{2}$ van arribar als valors de repòs $(3,5 \mathrm{~mL} / \mathrm{kg} /$ min) durant com a mínim $30 \mathrm{~s}$. L'EPOC es va mesurar com el consum d'oxigen $\left(\mathrm{VO}_{2}\right)$ des del començament de la recuperació fins que es van aconseguir els esmentats valors de repòs. El volum de $\mathrm{O}_{2}$ total (L) consumit durant l'exercici i el període d'EPOC es van obtenir multiplicant el $\mathrm{VO}_{2}$ acumulat en ambdós períodes pel temps total (30 minuts d'exercici + temps de l'EPOC). La despesa calòrica es va trobar multiplicant el volum de $\mathrm{O}_{2}$ total consumit (L) per 5 (en atorgar un equivalent calòric de $5 \mathrm{kcal}$ a cada $\mathrm{L}$ de $\mathrm{O}_{2}$ consumit).

\section{Anàlisi estadística}

Es va comparar el treball total realitzat amb una prova paramètrica de mesures repetides (test de Student) entre l'exercici d'intervals i l'exercici continu, aíxí com la despesa calòrica (kcal): 1) durant l'exercici en si; 2) en l'EPOC, i 3) en la suma de 1) i 2) (despesa calòrica total).

El consum d'oxigen total postexercici, així com el quocient respiratori (RER) i la FC van ser analitzats usant una anàlisi de la variància (ANOVA) de dues vies per a mesures repetides. Quan l'ANOVA oferia diferències significatives es van utilitzar correccions post hoc per a comparacions múltiples (Newman-Kleus test). El nivell de significació es va establir per alfa $=0,05$. Per a l'anàlisi de dades estadístiques es va utilitzar el software SPSS 16.0 (SPSS Inc., Chicago, IL, USA).

\section{Resultats}

Els valors basals anteriors als dos tipus d'exercici, d'intervals $\mathrm{i}$ continu van ser similars per a $\mathrm{VO}_{2}(\mathrm{CON}$ : $269 \pm 48 \mathrm{ml} / \mathrm{min}^{-1}$, INT: $\left.275 \pm 51 \mathrm{ml} / \mathrm{min}^{-1}\right)$, RER (CON: $0,85 \pm 0,08$, INT: $0,86 \pm 0,07)$ i FC (CON: $58 \pm 10$ ppm, INT: $59 \pm 9$ ppm) i van demostrar que els subjectes van començar els exercicis en situacions fisiològiques comparables. Aquestes dades són similars a les que van trobar Chad i Quigley (1991) i McGarvey et al. (2005). Les dades en exercici es mostren en la taula 1. El treball total va ser similar en ambdós tractaments (CON: 358,60ロ70,82 kJ, INT: $352,99 \pm 63,56 \mathrm{~kJ}$ ) i no es van trobar entre ells diferències significatives.

El consum calòric total va ser significativament més gran $(P=0,038)$ en l'exercici d'intervals $(398,5 \pm 98,5 \mathrm{kcal})$ que en el continu $(343,2 \pm 75,3 \mathrm{kcal})$ (taula 1), fet que corrobora la nostra hipòtesi i demostra que l'exercici d'intervals ha de ser tingut en compte a l'hora de programar exercici per a la pèrdua de pes i contradient els resultats de McGarvey et al. (2005). El consum calòric en exercici va ser significativament més gran $(P=0,016)$ en l'exercici d'intervals $(315,7 \pm 53,1 \mathrm{kcal})$ que en el continu $(289,7 \pm 60 \mathrm{kcal})$ (taula 1) per a distàncies i treball total similars (taula 1), fet que demostra que l'exercici d'intervals és més eficaç. El consum calòric en la recuperació va ser més gran $(P=0,031)$ en l'exercici d'intervals $(85 \pm 66,8 \mathrm{Kcal})$ que en el continu $(43,5 \pm 26,8 \mathrm{Kcal}$ ) (taula 1 ), factor que explica la importància de realitzar un exercici d'intervals per als tipus de programes específics de pèrdua de pes, ja que l'excés de despesa energètica es produeix durant la recuperació sense ocasionar trastorns al subjecte. La freqüència cardíaca mitjana total va ser

\begin{tabular}{|c|c|c|c|c|c|c|c|c|c|c|c|c|}
\hline Tipus d'exercici & $\begin{array}{c}V E \\
\text { mitjana } \\
\text { total } \\
(\mathrm{L} / \mathrm{min})\end{array}$ & $\begin{array}{c}V E \\
\text { mitjana } \\
\text { en exercici } \\
(L / \text { min) }\end{array}$ & $\begin{array}{c}V E \\
\text { mitjana } \\
\text { en recupe- } \\
\text { ració } \\
(L / \text { min })\end{array}$ & $\begin{array}{l}\text { Distància } \\
\text { recorreguda } \\
\text { (m) }\end{array}$ & $\begin{array}{c}\text { Despesa } \\
\text { calòrica } \\
\text { total } \\
\text { (kcal) }\end{array}$ & $\begin{array}{c}\text { Despesa } \\
\text { calòrica } \\
\text { exercici } \\
\text { (kcal) }\end{array}$ & $\begin{array}{c}\text { Despesa } \\
\text { calòrica } \\
\text { recupe- } \\
\text { ració } \\
\text { (kcal) }\end{array}$ & $\begin{array}{c}\text { FC } \\
\text { total } \\
(I \mathrm{lpm})\end{array}$ & $\begin{array}{c}F C \\
\text { exercici } \\
(I p m)\end{array}$ & $\begin{array}{c}\text { FC } \\
\text { recupe- } \\
\text { ració } \\
(I p m)\end{array}$ & $\begin{array}{l}\text { Temps } \\
\text { de recupe- } \\
\text { ració } \\
\text { (s) }\end{array}$ & $\begin{array}{c}\text { Treball } \\
(\mathrm{kJ})\end{array}$ \\
\hline D'intervals & $\begin{array}{c}52,7 \\
\pm \\
8,6 *\end{array}$ & $\begin{array}{c}64,6 \\
\pm \\
11,3 *\end{array}$ & $\begin{array}{c}19,5 \\
\pm \\
3,6\end{array}$ & $\begin{array}{c}3.700 \\
\pm \\
289\end{array}$ & $\begin{array}{c}398,5 \\
\pm \\
98,5 *\end{array}$ & $\begin{array}{c}315,7 \\
\pm \\
53,1^{*}\end{array}$ & $\begin{array}{c}85 \\
\pm \\
66,8^{*}\end{array}$ & $\begin{array}{c}149,7 \\
\pm \\
7^{*}\end{array}$ & $\begin{array}{c}162,2 \\
\pm \\
4,1^{*}\end{array}$ & $\begin{array}{c}111,4 \\
\pm \\
11,5^{*}\end{array}$ & $\begin{array}{c}1.032 \\
\pm \\
468 *\end{array}$ & $\begin{array}{c}352,99 \\
\pm \\
63,56\end{array}$ \\
\hline Continu & $\begin{array}{c}42 \\
\pm \\
9\end{array}$ & $\begin{array}{c}45,4 \\
\pm \\
8,6\end{array}$ & $\begin{array}{c}19,2 \\
\pm \\
9,8\end{array}$ & $\begin{array}{c}3.725 \\
\pm \\
380\end{array}$ & $\begin{array}{c}343,2 \\
\pm \\
75,3\end{array}$ & $\begin{array}{c}289,7 \\
\pm \\
60\end{array}$ & $\begin{array}{c}43,5 \\
\pm \\
26,8\end{array}$ & $\begin{array}{c}133 \\
\pm \\
4\end{array}$ & $\begin{array}{c}137,2 \\
\pm \\
2,6\end{array}$ & $\begin{array}{c}100 \\
\pm \\
7,3\end{array}$ & $\begin{array}{c}552 \\
\pm \\
324\end{array}$ & $\begin{array}{c}358,60 \\
\pm \\
70,82\end{array}$ \\
\hline $\begin{array}{l}\text { Kcal: kilocalori } \\
\text { * Diferències }\end{array}$ & $\begin{array}{l}\text { Ipm: ba } \\
\text { ificative }\end{array}$ & $\begin{array}{l}\text { s per minu } \\
\text { ntre tracta }\end{array}$ & $\begin{array}{l}\text { : segons; } \\
\text { nts; } P<0\end{array}$ & $\begin{array}{l}\text { freqüènci } \\
5 .\end{array}$ & cardíaca & min: litre & ninut; & ventilac & & & & \\
\hline
\end{tabular}


significativament més gran $(P=0,00)$ en l'exercici d'intervals $(149 \pm 7 \mathrm{lpm})$ que en el continu $(133 \pm 4 \mathrm{lpm})$ (taula 1); aquest augment de freqüència cardíaca, així com els valors màxims aconseguits, proporcionen al subjecte adaptacions importants per a la salut $(6,12,31)$. La freqüència cardíaca mitjana en exercici va ser significativament més gran $(P=0,05)$ en l'exercici d'intervals $(162,2 \pm 4,1 \mathrm{lpm})$ que en el continu $(137,2 \pm 2,6 \mathrm{lpm})$ (taula 1). La freqüència cardíaca mitjana en la recuperació va ser significativament més gran $(P=0,039)$ en l'exercici d'intervals $(111 \pm 11 \mathrm{lpm})$ que en el continu $(100 \pm 7 \mathrm{lpm})$ (taula 1$)$. El temps de recuperació va ser significativament més gran $(P=0,017)$ en l'exercici d'intervals $(1032 \pm 468$ s) que en el continu $(552 \pm 324 \mathrm{~s})$ (taula 1). I la ventilació mitjana total va ser significativament més gran $(P=0,007)$ en el d'intervals $(52,7 \pm 8,6 \mathrm{~L} / \mathrm{min}$.) que en el continu $(42 \pm 9 \mathrm{~L} / \mathrm{min})$ (taula 1). La ventilació en la recuperació va ser similar $(P=0,928)$ en l'exercici d'intervals $(19,5 \pm 3,6 \mathrm{~L} / \mathrm{min})$ $i$ en el continu $(19,2 \pm 9,8 \mathrm{~L} / \mathrm{min}$ ) (taula 1$)$. La distància recorreguda va ser similar en ambdós casos, en l'exercici d'intervals es va arribar a $3.700 \pm 289 \mathrm{~m}$ i en el continu a $3.725 \pm 380 \mathrm{~m}$, i es va demostrar quina distància total recorreguda va ser similar en ambdós tractaments, situació indispensable a l'hora de comparar ambdós tipus d'exercici en igualtat de condicions.

\section{Discussió}

En aquest estudi hem comparat la despesa calòrica total (exercici + recuperació) d'un exercici continu de baixa intensitat $\left(65 \% \mathrm{VO}_{2 \max }\right)$ amb el d'un exercici d'intervals d'alta intensitat $\left(90 \% \mathrm{VO}_{2 \text { màx }}\right)$. Els resultats van mostrar com l'exercici d'intervals produïa una despesa calòrica total significativament major que l'exercici continu, la qual cosa ens indica que els beneficis que l'exercici aporta des del punt de vista de la salut serien més grans amb l'exercici d'intervals tenint en compte el principi citat per Hardman (2001): "l'energia total consumida en un exercici és el principal determinant de la seva influència sobre la salut". Hardman mostra el major increment del $\mathrm{VO}_{2}$ produït per l'exercici d'intervals en comparació amb l'exercici continu, la qual cosa es tradueix en més beneficis per a la salut dels subjectes. No obstant això, la major part de l'energia que els nostres subjectes van consumir corresponia a l'exercici en si: el $79 \%$ i el $84 \%$ de l'energia total va ser consumit durant l'exercici d'intervals i continu, respectivament, enfront del $21 \%$ i el $16 \%$ de la despesa postexercici d'intervals i continu, respectivament. Aquests resultats concorden amb les dades recollides per altres autors (Almuzaini et al., 1998; Gore \& Withers, 1990; Maresh et al., 1992; Schuenke et al., 2002; Uusitalo et al., 1998). D'altra banda, hem de tenir en compte que l'exercici d'intervals només produirà els esmentats beneficis quan es realitza a intensitats altes ("períodes curts d'exercici d'alta intensitat produeixen beneficis en la salut quan aquests provoquen un alt consum d'energia") (Hardman, 2001).

Els nostres resultats també mostren que l'exercici d'intervals produeix majors augments en el temps de recuperació que l'exercici continu com ja van exposar Gore i Withers (1990), Bahr et al. (1987) i Sedlock (1994). No obstant això, els nostres resultats mostren unes diferències una mica menors que aquests estudis, ja que trobem recuperacions de $30 \mathrm{~min}$, en contraposició a recuperacions més llargues (per exemple, de fins a $9 \mathrm{~h}$ en un estudi en atletes exercitant-se a altíssimes intensitats $(20 \mathrm{~min}$ al $105 \% \mathrm{VO}_{2 \operatorname{màx}}$ ) (LaForgia et al., 1997).

El major consum d'oxigen en la recuperació després de l'exercici d'intervals es deu a increments en diferents variables. Tradicionalment, es pensava que el deute d'oxigen depenia sobretot de dos factors diferents: 1) el deute làctic d'oxigen atribuïble a l'oxidació del lactat produït en l'exercici (per restablir els dipòsits de glucogen hepàtic a partir del lactat (Cicle de Cori) i per depurar el lactat restant a través del cicle de l'àcid pirúvic), i 2) el deute làctic d'oxigen que no es relaciona amb l'acumulació de lactat en l'exercici, sinó amb el restabliment dels valors intramusculars d'ATP i fosfocreatina $(\mathrm{PCr}) \mathrm{i}$ en menor mesura amb el restabliment dels dipòsits d'oxigen en la mioglobina muscular i en l'hemoglobina sanguínia (McArdle, Katch, \& Katch, 2001). Avui dia veiem que el lactat perd força importància en la duració de l'EPOC i sabem que la resíntesi de lactat a glucogen representa un petit percentatge de l'EPOC, ja que aquest mecanisme es realitza durant l'exercici, sobretot en esportistes entrenats. A més a més, el reestabliment dels magatzems de glucogen es deu en la seva major part a la dieta i no al lactat. En l'actualitat, la temperatura corporal assoleix més protagonisme en la duració i magnitud de l'EPOC, ja que manté augmentat el metabolisme (com ocorre en estats febrils). Aquest augment en la temperatura es deu a l'alliberament de calor durant la producció d'ATP (Kaminsky et al., 1990). La diferència de l'augment de temperatura en ambdós tractaments deu ser, per tant, un factor que cal tenir en compte, si ens basem en el fet que la temperatura corporal augmenta 
conforme ho fa la intensitat de l'exercici (McArdle et al., 2001) i arriba a nivells de $39^{\circ} \mathrm{C}$ a intensitats superiors al $75 \%$ del $\mathrm{VO}_{2 \text { màx }}$ (que serien més baixes que la intensitat escollida per al nostre exercici d'intervals) i nivells de $38{ }^{\circ} \mathrm{C}$ a intensitats del $50 \% \mathrm{VO}_{2 \text { màx }}$ (és a dir, a intensitats properes a les del nostre exercici continu). El $10 \%$ de la magnitud de l'EPOC és atribuïble al retorn als pulmons de volums de sang dels teixits actius durant l'exercici, i un 2-5\% de l'EPOC és atribuïble al restabliment dels nivells basals d'oxigen sanguini i muscular. La ventilació contribueix en un $10 \%$. També hem de tenir en compte la redistribució del calci, el potassi i el sodi o l'augment de la freqüència cardíaca, de l'activitat hormonal (epinefrina, norepinefrina i tiroxina) i dels glucocorticoides. Per exemple, A. L. Uusitalo, Huttunen, Hanin i Uusitalo (1998) van trobar diferències entre els nivells postexercici de cortisol, catecolamines i testosterona, essent majors en exercici màxim que en exercici submàxim i que en repòs.

La freqüència cardíaca també va ser significativament major en l'exercici d'intervals que en el continu tant en el total $(149,7 \pm 7 \mathrm{lpm}$ versus $133 \pm 4 \mathrm{lpm})$ com durant l'exercici $(162,2 \pm 4,1 \mathrm{lpm}$ versus $137,2 \pm 2,6 \mathrm{lpm}) \mathrm{i}$ la recuperació $(111,4 \pm 11,5 \mathrm{lpm}$ vs. $100 \pm 7,3 \mathrm{lpm})$. Aquestes dades concorden amb les obtingudes per LaForgia, Withers, Shipp i Gore (1997). De totes maneres, encara no està completament aclarida la contribució relativa de la freqüència cardíaca en la depesa calòrica postexercici, posat que és una variable que mostra importants variacions individuals (McArdle et al., 2001).

Els valors de ventilació també van ser significativament majors en el cas de l'exercici d'intervals $(52,7+8,6 \mathrm{~L} / \mathrm{min}$ versus $42+9 \mathrm{~L} / \mathrm{min})$, la qual cosa concorda amb les dades obtingudes quant a consum energètic i freqüència cardíaca. El poder de tamponament de la ventilació dobla en importància els efectes químics de tamponament buffer de la sang, per això és important l'augment de la ventilació en l'exercici d'intervals $\left(95 \% \mathrm{FC}_{\text {màx }}\right)$, en què es produeixen majors descensos del pH en comparació amb l'exercici continu $\left(70 \% \mathrm{FC}_{\text {màx }}\right)$. Augmentant la ventilació en repòs s'aconsegueix augmentar en 0,23 unitats l'alcalinitat, passant el $\mathrm{pH}$ de 7,40 a 7,63 i viceversa (McArdle et al. 2001). Aquest augment de la ventilació en l'exercici d'intervals $\left(95 \% \mathrm{FC}_{\text {màx }}\right)$ amb l'objectiu, en part, de disminuir el $\mathrm{pH}$ muscular provoca, a la vegada, un augment en el $\mathrm{VO}_{2}$, ja que els músculs respiratoris són responsables del $10 \%$ del $\mathrm{VO}_{2}$ total (Williams, Wongsathikum, Boon, \& Acevedo, 2002; Yoshida et al., 1990).
Totes aquestes dades ens aporten evidències suficients per plantejar-nos la importància de l'exercici d'intervals per preescriure activitat física en obesos, en què el principal objectiu és aconseguir una despesa calòrica més gran en el menor temps possible sense provocar cap prejudici per a la salut. És important replantejar-se l'exercici en aquest tipus de població i començar a dissenyar un treball en el qual s'arribi progressivament a intensitats altes on els beneficis per a la salut són avui dia inqüestionables, ja que, a més a més d'augmentar la despesa calòrica amb els seus consegüents beneficis despresos de la cita anterior de Hardman (2001) i aconseguir una major pèrdua de pes, podem obtenir millores en el consum d'oxigen molt majors que si l'exercici realitzat fos únicament aeròbic o continu. S'ha demostrat que un augment en el $\mathrm{VO}_{2}$ augmenta en diversos anys les expectatives de vida $\mathrm{i}$, per tant, pensem que aquest tipus d'exercici ha de ser part indispensable de qualsevol programa d'exercici sense oblidar que l'exercici ha de ser de baixa intensitat o aeròbic, la base de qualsevol programa d'activitat física. No obstant això, les nostres dades entren en contraposició amb les obtingudes recentment per McGarvey et al. (2005) que demostren que en l'exercici en cicloergòmetre i comparant dues situacions similars a les nostres $\left(65 \% \mathrm{VO}_{2 \text { màx }}\right.$ i $\left.90 \% \mathrm{VO}_{2 \text { màx }}\right)$ no es troben diferències significatives ni en la quantificació de la despesa calòrica total ni en la recuperació. Al nostre entendre, els resultats poden ser deguts a un major augment de la temperatura corporal durant un exercici en tapís rodant en què entren en joc més quantitat de grups musculars i la magnitud de l'EPOC es veu incrementada fins que la temperatura aconsegueix valors de repòs. Així mateix, la temperatura ambient va ser major en el nostre estudi que en el de McGarvey et al. (2005) $\left(26^{\circ} \mathrm{C}\right.$ versus $\left.23,5^{\circ} \mathrm{C}\right)$, la qual cosa també portaria a majors temperatures aconseguides pels subjectes. No obstant això, es recomana per a futures investigacions el mesurament de la temperatura mitjana i total de dos tipus d'exercici per poder comparar-ne els resultats.

En conclusió, en aquest estudi es demostra que la despesa calòrica total és més gran en un exercici d'intervals d'alta intensitat que en un exercici continu de baixa intensitat per a temps $i$ càrregues de treball iguals. A més, la despesa calòrica en l'exercici d'intervals és més gran tant durant l'exercici com durant la recuperació, essent molt més important la despesa que es produeix durant l'exercici que el que es produeix durant la recuperació. 


\section{Referències}

Almuzaini, K. S., Potteiger, J. A., \& Green, S. B. (1998). Effects of split exercise sessions on excess postexercise oxygen consumption and resting metabolic rate. Canadian Society for Exercise Physiology, 23(5), 433-43. doi:10.1139/h98-026

Bahr, R., Ingnes, I., Vaage, O., Sejersted, O. M., \& Newsholme, E. A. (1987). Effect of duration of exercise on excess postexercise $\mathrm{O}_{2}$ consumption. European Journal of Applied Physiology, 62(2), 485-90.

Binzen, C. A., Swan, P. D., \& Manore, M. M. (2001). Postexercise oxygen consumption and substrate use after resistance exercise in women. Medicine and science in sports and exercise, 33(6), 932-8. do :10.1097/00005768-200106000-00012

Borsheim, E. \& Bahr, R. (2003). Effect of exercise intensity, duration and mode on post-exercise oxygen consumption. Sports medicine (Auckland, N.Z.), 33(14), 1037-60. doi:10.2165/00007256-200333140-00002

Brockman, L., Berg, K., \& Latin, R. (1993). Oxygen uptake during recovery from intense intermittent running and prolonged walking. The Journal of Sports Medicine and Physical Fitness, 33(4), 330-336.

Chad, K. E. \& Quigley, B. M. (1991). Exercise intensity: Effect on postexercise $\mathrm{O}_{2}$ uptake in trained and untrained women. European Journal of Applied Physiology, 70(4), 1713-1719.

Covertino, V. A. (1991). Blood volume: its adaptation to endurance training. Medicine and Science in Sports and Exercise, 23(12), 13381348.

Friedlander, A. L., Casazza, G. A., \& Horning, M. A. (1998). Effects of exercise intensity and training on lipid metabolism in young women. American Journal of Physiology. Endocrinology and Metabolism, 275(5), E853-E863.

Gaesser, G. A. \& Brooks, G. A. (1984). Metabolics basis of excess post-exercise oxygen consumption: a review. Medicine and Science in Sports and Exercise, 16(1), 29-43.

Gerardo, J., Córdova, A., \& González, J. (2000). Nutrición del deportista. Madrid: Gymnos.

González-Alonso, J., Quistorff, B., Krustrup, P., \& Saltin, B. (2000). Heat production in human skeletal muscle at the onset of intense dynamic exercise. The Journal of Physiology, 524(Pt. 2), 603-15. doi:10.1111/j.1469-7793.2000.00603.x

Gore, C. J. \& Withers, R. T. (1990). Effect of exercise intensity and duration on postexercise metabolism. Journal of Applied Physiology, 68(6), 2362-8.

Guesbeck, N. R., Hickey, M. S., MacDonald, K. G., Pories, W. J., Harper, I., Ravussin, E., ... Houmard, J. A. (2001). Substrate utilization during exercise in formerly morbidly obese women. Journal of applied physiology, 90(3), 1007-12.

Haltom, R. W., Kraemer, R. R., Sloan, R. A., Hebert, E. P., Frank, K., \& Tryniecki, J. L. (Novembre 1999). Circuit weight training and its effects on excess postexercise oxygen consumption. Medicine and Science in Sports and Exercise, 31(11), 1613-8. doi:10.1097/00005768-199911000-00018

Hardman, A. E. (2001). Issues of fractionization of exercise (short vs long bouts). Medicine and Science in Sports and Exercise, 33(6 Supl.), S421-S427.

Horowitz, J. F. \& Klein, S. (2000). Oxidation of nonplasma fatty acids during exercise is increased in women with abdominal obesity. Journal of Applied Physiology, 89(6), 2276-2282.

Horton, T. J., Pagliassotti, M. J., Hobbs, K., \& Hill, J. O. (1998). Fuel metabolism in men and women during and after long-duration exercise. Journal of Applied Physiology, 85(5), 1823-1832.

Kaminsky, L. A., Padjen, S., \& LaHam-Saeger, J. (1990). Effect of split sessions on excess post-exercise oxygen consumption. British Journal of Sports Medicine, 24(2), 95-§. doi:10.1136/bjsm.24.2.95
LaForgia, J., Withers, R. T., Shipp, N. J., \& Gore, C. J. (1997). Comparison of energy expenditure elevations after submaximal and supramaximal running. Journal of Applied Physiology, 82(2), 661666.

Maresh, C. M., Abraham, A., De Souza, M. J., Deschenes, M. R., Kraemer, W. J., Armstrong, L. E., ... Hoffman, J. R. (1992). Oxygen consumption following exercise of moderate intensity and duration. European Journal of Applied Physiology and Occupational Physiology, 65(5), 421- . doi:10.1007/BF00243508

McArdle, W. D., Katch, F. I., \& Katch, V. L. (2001). Exercise Physiology: Energy, Nutrition, and Human Performance (5a ed.). Philadelphia, USA: Lippincott Williams and Wilkins.

McGarvey, W., Jones, R., \& Petersen, S. (2005). Excess Post-Exercise oxygen consumption following continuous and interval cycling exercise. International Journal of Sports Nutrition and Exercise Metabolism, 15(1), 28-37.

Melanson, E. L., Sharp, T. A., Seagle, H. M., Horton, T. J., Donahoo, W. T., Grunwald, G. K., ... Hill, J. O. (2002). Effect of exercise intensity on 24-h energy expenditure and nutrient oxidation. Journal of Applied Physiology, 92(3), 1045-52.

Phillips, S. M., Green, H. J., \& Tarnopolsky, M. A. (1996). Effects of training duration on substrate turnover and oxidation during exercise. Journal of Applied Physiology, 81(5), 2182-2191.

Pritzlaff, C. J., Wideman, L., Blumer, J., Jensen, M., Abbott, R. D., Gaesser, G. A., ... Welman, A. (2000). Catecholamine release, growth hormone secretion, and energy expenditure during exercise vs. recovery in men. Journal of Applied Physiology, 89(3), 937-946.

Romijn, J. A., Coyle, E. F., Sidossis, L. S., Rosenblatt, J., \& Wolfe, R. R. (2000). Substrate metabolism during different exercise intensities in endurance-trained women. Journal of Applied Physiology, 88(5), 1707-1714.

Schuenke, M. D., Mikat, R. P., \& McBride, J. M. (2002). Effect of an acute period of resistance exercise on excess post-exercise oxygen consumption: Implications for body mass management. Journal of Applied Physiology, 86(5), 411-7.

Sedlock, D. A. (1994). Fitness level and postexercise energy expenditure. The Journal of Sports Medicine and Physical Fitness, 34(4), 336-342.

Sedlock, D. A., Fissinger, J. A., \& Melby, C. L. (1989). Effect of exercise intensity and duration on postexercise energy expenditure. Medicine and Science in Sports and Exercise, 21(6), 662-666.

Thornton, M. K. \& Potteiger, J. A. (2002). Effects of resistance exercise bouts of different intensities but equal work on EPOC. Medicine and Science in Sports and Exercise, 34(4), 715-22. doi:10.1097/00005768-200204000-00024

Uusitalo, A. L., Huttunen, P., Hanin, Y., \& Uusitalo, A. J. (1998). Hormonal responses to endurance training and overtraining in female athletes. Clinical Journal of Sport Medicine, 8(3), 178-86. doi:10.1097/00042752-199807000-00004

Williams, J. S., Wongsathikum, J., Boon, S. M., \& Acevedo, E. O. (2002). Inspiratory muscle training fails to improve endurance capacity in athletes. Medicine and Science in Sports and Exercise, 34(7), 1194-8 doi:10.1097/00005768-200207000-00022

Yoshida, T., Chida, M., Ichioka, M., Makiguchi, K., Eguchi, J., \& Udo, M. (1990). Relatinoship between ventilation and arterial potassium concentration during incremental exercise and recovery. European Journal of Applied Physiology and Occupational Physiology, 61(3-4), 193-6. doi:10.1007/BF00357598

Weltman, A., Weltman, J., Rutt, R., Seip, R., Levine, S., Snead, D., ... Rogol, A. (1989). Percentages of maximal heart rate reserve, and $\mathrm{VO}_{2}$ peak for determining endurance training intensity in sedentary women. International Journal of Sports Medicine, 10(3), 212-6. dd i: $10.1055 / \mathrm{s}-2007-1024903$ 